\title{
Variability and Climatology of PWV From Global 13-Year GPS Observations
}

\author{
Shuanggen Jin, Member, IEEE, and O. F. Luo
}

\begin{abstract}
Water vapor plays the key role in the global hydrologic cycle and climate change. However, the distribution and variability of water vapor in the troposphere is not understood well in the globe, particularly the high-resolution variation. In this paper, 13-year 2-h precipitable water vapors (PWV) are derived from globally distributed 155 Global Positioning System sites observations and global three-hourly surface weather data and six-hourly National Centers for Environmental Prediction/National Center for Atmospheric Research reanalysis products, which are the first used to investigate multiscale water-vapor variability on a global scale. It has been found that the distinct seasonal cycles are in summer with a maximum water vapor and in winter with a minimum water vapor. The higher amplitudes of annual PWV variations are located in midlatitudes with about 10-20 $\pm 0.5 \mathrm{~mm}$, and the lower amplitudes are found in high latitudes and equatorial areas with about $5 \pm 0.5 \mathbf{~ m m}$. The larger differences of mean PWV between in summer and winter are located in midlatitudes with about 10-30 mm, particularly in the Northern Hemisphere. The semiannual variation amplitudes are relatively weaker with about $0.5 \pm 0.2 \mathrm{~mm}$. In addition, significant diurnal variations of PWV are found over most International Global Navigation Satellite Systems Service stations. The diurnal $(24 \mathrm{~h})$ cycle has amplitude of $0.2-1.2 \pm 0.1 \mathrm{~mm}$, and the peak time is from the noon to midnight. The semidiurnal $(12 \mathrm{~h})$ cycle is weaker, with amplitude of less than $0.3 \mathrm{~mm}$.
\end{abstract}

Index Terms-Climatology, Global Positioning System (GPS), variability, water vapor.

\section{INTRODUCTION}

W ATER vapor plays a central role in atmospheric radiation, energy balance, and thermodynamics, and the hydrological cycle and is the most abundant greenhouse gas. The water-vapor storage in the column of the atmosphere in terms of water budget is the precipitable water vapor (PWV) as a result of the balance between precipitation, evaporation, and convergence of humidity [1]. It is an important indicator of watervapor climatology and variability in the lower troposphere and related climate processes. PWV concentrations vary with high degree of spatial and temporal variability, depending upon the season, topography and other local and regional climatic conditions. Therefore, it is vital to measure PWV and understand its

Manuscript received September 3, 2008; revised October 1, 2008. First published April 7, 2009; current version published June 19, 2009. This work was supported by the Korea Research Council of Fundamental Science and Technology Grant.

S. Jin is with the Korea Astronomy and Space Science Institute, Daejeon 305-348, Korea, and also with the Center for Space Research, University of Texas at Austin, Austin, TX 78759-5321 USA (e-mail: sgjin@kasi.re.kr; sg.jin@yahoo.com).

O. F. Luo is with the Chungnam National University, Daejeon 305-764, Korea (e-mail: ofluo@hotmail.com).

Color versions of one or more of the figures in this paper are available online at http://ieeexplore.ieee.org.

Digital Object Identifier 10.1109/TGRS.2008.2010401 variability, but such advancements were restricted until balloonborne radiosonde data [1], [2], and satellite observations from either infrared sounders or microwave radiometers [4] became available. Although in the past time many people investigated water-vapor climatology with radiosonde and satellite observations, unfortunately, such observations are still limited in watervapor climate studies, particularly the high-resolution diurnal variations due to the poor quality radiosonde and a lack of high spatial-temporal resolution observations [5], [6]. For example, the Special Sensor Microwave/Imager (SSM/I) radiometers on the Defense Meteorological Satellite Program Block 5D-2F8 spacecraft can provide the precipitation water vapor over the globe. However, SSM/I covers the whole globe in two days with some gaps in data [7].

Nowadays, the Global Positioning System (GPS) has been widely developed as an all-weather, high spatial-temporal resolution and low-cost remote-sensing system of the atmosphere [8]-[13], as compared to conventional techniques such as satellite radiometer sounding, microwave radiometer, and radiosondes [14]. With independent data from other instruments, in particular water-vapor radiometers, it has been demonstrated that the water vapor can be retrieved using groundbased GPS observations at the same level of accuracy as radiosondes and microwave radiometers [15]-[20]. Therefore, the GPS-derived water vapors have been widely applied in meteorology and climatology, e.g., numeric weather prediction model improvement [21], [22] and studying diurnal variations of PWV [23], [24]. Particularly, the expanding permanent International Global Navigation Satellite Systems Service (IGS) GPS network provides an important data source to study water-vapor climatology and variability on a global scale. However, the current water vapor cannot be directly derived from global IGS GPS network observations without colocated meteorological measurements. Even when available, colocated surface meteorological data can be very noisy and cannot be used without careful examination and quality control. Recently, the PWV over GPS sites without colocated meteorological observations can be retrieved using the interpolated site specific surface meteorological parameters from the European Centre for medium range weather forecast (ECMWF) or the National Centers for Environmental Prediction/ National Center for Atmospheric Research (NCEP/NCAR) global reanalysis products. For example, Schueler et al. [25] has derived the integrated water vapor using the interpolated site specific surface meteorological parameters from the numerical weather fields of NCEP Global Data Assimilation System $1^{\circ} \times 1^{\circ}$ grid. Wang et al. [26] have developed the analysis technique to obtain water vapor from the IGS tropospheric 


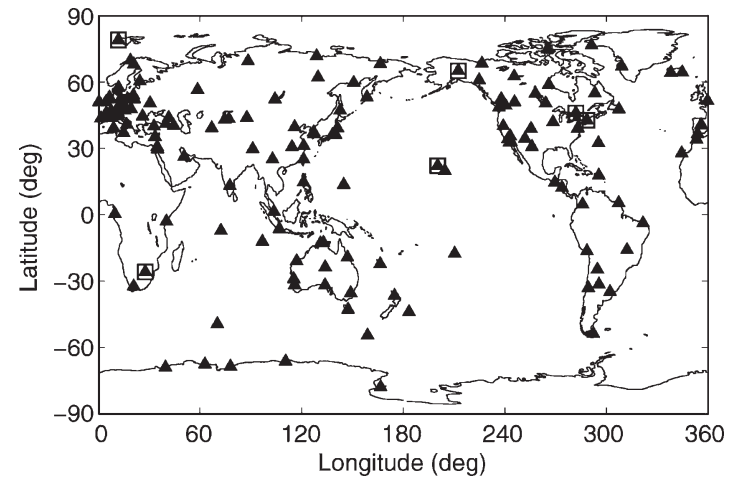

Fig. 1. Distribution of globally distributed IGS GPS sites (marked with bold triangles) and colocated VLBI sites (marked with blank squares).

delay products using different available meteorological data sets with interpolation techniques. The aforementioned studies demonstrated the feasibility of ground-based GPS network and interpolated meteorological data for water-vapor estimation.

In this paper, the 13-year PWV data on a global scale derived from the currently existing global IGS GPS network measurements for 1994-2007 and numerical weather model's reanalysis products are the first used to investigate the annual and diurnal variability of water vapor on a global scale. In the following section, the procedure of 13-year PWV retrieval is briefly described. Water-vapor variability and climatology on a global scale are given in Section III as well as conclusions in the final section.

\section{PWV DATA}

\section{A. PWV From IGS-Based GPS Measurements}

The IGS was formally established in 1993 by the International Association of Geodesy, and began routine operations on January 1, 1994 [27]. The IGS has operated a worldwide network of permanent tracking stations with more than 350 GPS sites, and each equipped with a GPS receiver, providing raw GPS orbit and tracking data as a data format called Receiver Independent Exchange. All available near-real-time global IGS observation data are transmitted to Global IGS Data Centers (e.g., the fourth GDC at the Korea Astronomy and Space Science Institute (http://gdc.kasi.re.kr). Since 1998, the IGS regularly generates a combined tropospheric product in the form of weekly files containing the zenith tropospheric delay (ZTD) at a 2-h time interval from the IGS tracking stations (ftp://cddis.gsfc.nasa.gov/gps/products/trop_new). However, the ZTD products before 1998 are not available, and moreover, Humphreys et al. [28] demonstrated a drastically attenuated oscillation in the IGS-provided ZTD products between during 1997-2000 and 2000-2004, which was probably caused by the computed ZTD algorithm and network evolution. This paper selects the globally distributed 155 IGS sites with better and continuous observations spanning at least five years (Fig. 1), and most sites observations are from 1997 to 2007 (ftp://nfs.kasi.re.kr). The GPS observation data suffering earthquake or monument/antenna changes are removed after checking GPS sites logs. The 13-year ZTD parameters at a temporal resolution of $2 \mathrm{~h}$ are obtained from continuous IGS GPS network observations (1994-2007) using GAMIT software [29] and the newly recommended strategies [13], [30], [31]. The IGS final orbits, International Earth rotation and Reference systems Service earth orientation parameters, azimuth- and elevationdependent antenna phase center models as recommended by the IGS were used in the data processing. The mean uncertainty of ZTD is about $1.8 \mathrm{~mm}$. Comparing with IGS-provided combined ZTD from 1997-2007, our ZTD data are almost consistent with a mean root mean square (rms) of about $1.5 \mathrm{~mm}$.

The ZTD is the integrated refractivity along a vertical path through the neutral atmosphere

$$
Z T D=c \tau=10^{-6} \int_{0}^{\infty} N(s) d s
$$

where $c$ is the speed of light in a vacuum, $\tau$ is the delay measured in units of time, and $N$ is the neutral atmospheric refractivity. The refractivity $N$ is empirically related to standard meteorological variables as [31]

$$
N=k_{1} \rho+k_{2} \frac{P_{\mathrm{w}}}{Z_{\mathrm{w}} T}+k_{3} \frac{P_{\mathrm{w}}}{Z_{\mathrm{w}} T^{2}}
$$

where $k_{i}(i=1,2,3)$ are the constant, $\rho$ is the total mass density of the atmosphere, $P_{\mathrm{w}}$ is the partial pressure of water vapor, $Z_{\mathrm{w}}$ is a compressibility factor close to unity accounting for the small departures of moist air from an ideal gas, and $T$ is the temperature in degree kelvin. The integral of the first term of (2) is the hydrostatic component $\left(N_{\mathrm{h}}\right)$ and the integral of the remaining two terms is the wet component $\left(N_{\mathrm{w}}\right)$. Thus, ZTD is the sum of the hydrostatic or dry delay (ZHD) and nonhydrostatic or wet delay (ZWD), due to the effects of dry gases and water vapor, respectively. The ZHD is related to the atmospheric pressure at the surface, i.e.,

$$
Z H D=2.2779 \times 10^{3} \frac{P_{\mathrm{s}}}{f(\lambda, H)}
$$

where $P_{\mathrm{s}}$ is the total surface pressure in millibars and $f(\lambda, H)$ is a factor for correcting the local gravity as $f(\lambda, H)=1-$ $0.00266 \cos (2 \lambda)-0.28 H$, where $\lambda$ is the latitude and $H$ is the height above the ellipsoid in meters. The wet component ZWD can be obtained by subtracting ZHD from ZTD, which can be transformed into the PWV via the following function [8]:

$$
P W V=\prod \cdot Z W D
$$

where $\prod=\left(10^{-6} \rho R_{\mathrm{v}}\left[\left(k_{3} / T_{\mathrm{m}}\right)+k_{2}^{\prime}\right]\right)^{-1}, \rho$ is the density of liquid water, $R_{\mathrm{v}}$ is the specific gas constant for water vapor, $T_{\mathrm{m}}$ is a weighted mean temperature of the atmosphere, $k_{2}^{\prime}=k_{2}-$ $m k_{1}$ and $m$ is $M_{\mathrm{w}} / M_{d}$, the ratio of the molar masses of water vapor and dry air [32]. Therefore, if the pressure and temperate data are available, the water vapor can be derived from GPSderived ZTD.

Due to the absence of local surface temperature and pressure data, the surface synoptic observations and numerical weather models' reanalysis products are used to calculate the $P_{\mathrm{s}}$ and $T_{\mathrm{m}}$. The $P_{\mathrm{s}}$ is interpolated from global $3-\mathrm{h}$ surface synoptic observations of all land and ocean surface weather stations with more than 15000 including in 


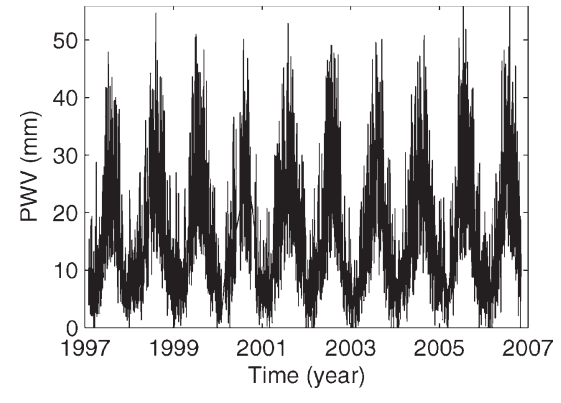

Fig. 2. PWV time series at ALGO, Canada.

the Global Telecommunication System and marine reports from the Comprehensive Ocean-Atmosphere Data Set [33] (http://dss.ucar.edu/datasets/ds464.0). The $T_{\mathrm{m}}$ should be the best estimated from the six-hourly reanalysis products ERA-40 (ECMWF 40-year reanalysis), but currently ERA-40 data are only available from 1948 to 2002, and the data after 2002 are not available. While the NCEP/NCAR reanalysis products are available from 1948 to present, and furthermore, the interpolated $T_{\mathrm{m}}$ results are almost similar with a small difference between ERA-40 and NCEP/NCAR reanalysis [26]. Therefore, in this paper the $2-\mathrm{h} T_{\mathrm{m}}$ is estimated from the six-hourly NCEP/NCAR reanalysis products (ftp://ftp.cdc. noaa.gov/Datasets/ncep.reanalysis) with an interpolation technique [26]. Thus, 2-h PWV time series for 1994-2007 over all global IGS sites can be derived from GPS-ZTD, surface synoptic observation-estimated $P_{\mathrm{S}}$ and NCEP/NCAR reanalysisestimated $T_{\mathrm{m}}$ with errors of about $1.0-1.5 \mathrm{~mm}$ due to errors in ZTD, Ps and Tm. Moreover, our GPS-derived PWV data are consistent with PWV estimates from IGS-provided combined ZTD (1997-2007) with an rms of less $0.2 \mathrm{~mm}$. For example, Fig. 2 shows the PWV time series at ALGO station (Canada).

\section{B. Comparison With Colocated Independent Observations}

The IGS GPS-derived PWV data are compared with another colocated independent technique-Very Long Baseline Interferometry (VLBI). Here, VLBI-PWV was derived from colocated meteorological observations data. Behrend et al. [34] analyzed about two weeks of data during December 1996 at Madrid (Spain) and found the ZTD differences between VLBI and GPS were smaller than $1 \mathrm{~cm}$. Snajdrova et al. [35] analyzed 15 continuous days of VLBI data during the Continuous VLBI 2002 (CONT02) campaign and found that the ZTD from VLBI and GPS were in good agreement at the 3-10 mm level as well as with the Doppler Orbitography Radio positioning Integrated by Satellite. Meanwhile, VLBIand GPS-observed ZTDs are also in quite good agreements with those from the ECMWFs and Water-Vapor Radiometry (WVR). Niell et al. [36] compared the results of a twoweek VLBI campaign in August 1995 (CONT95) at Westford (USA) with GPS, WVR and radiosondes and found the VLBI technique was the most accurate for the determination of ZTD. These show that the VLBI can obtain a high accuracy reliable ZTD estimation. The Analysis Centers (Acs) of the International VLBI Service (IVS) process all available VLBI observation data and corresponding products (e.g., ZTD) are

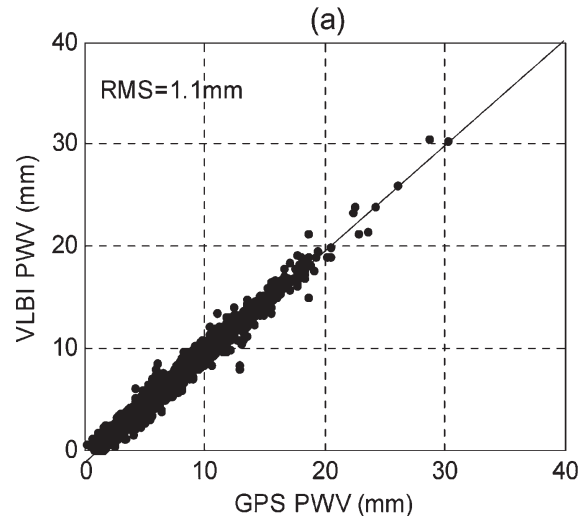

(b)

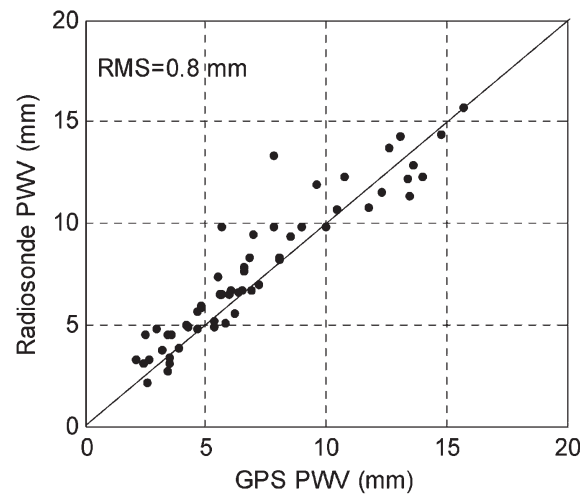

Fig. 3. Comparison of GPS-derived PWV with VLBI (upper panel) and radiosonde (bottom panel) at colocated station NYA1. (a) GPS and VLBI. (b) GPS and Radiosonde.

transferred to the IGG AC (Institute of Geodesy and Geophysics, Vienna University of Technology, Austria), for combination. The combined ZTD time series are available from IVS Data Centers (ftp://cddis.gsfc.nasa.gov/vlbi/ivsproducts/trop). Fig. 3(a) is comparison of three-year GPS and VLBI PWV data (2004-2007) at colocated station NYN1 (Norway). In total, the GPS-derived PWV agrees well with the colocated VLBI observations with an rms of less than $1.1 \mathrm{~mm}$. Moreover, the GPS-derived PWV data are almost consistent with the radionsonde at NYA1 (Norway) with an rms less than $0.8 \mathrm{~mm}$ [Fig. 3(b)].

\section{Results AND Discussion}

PWV is a key parameter of the atmosphere and varies with a high degree of spatial and temporal variability, depending upon the season, topography and other local and regional climatic conditions. The global high spatial-temporal resolution IGS observations provide an important water-vapor source to describe PWV distribution features and to understand its variability and change. The mean PWV at each IGS site was calculated from the 2-h PWV time series for whole 13 years, and their distributions are shown in Fig. 4. The mean water vapors are ranging from 5.0 to $60.0 \pm 1.2 \mathrm{~mm}$. The water vapor has a significant latitudinal distribution feature on a global scale. The larger water-vapor concentrations are located in low latitudes, particularly in tropical areas with about $30-60 \mathrm{~mm}$ and, generally, decrease to the high latitude with less than $15 \mathrm{~mm}$ north of $60^{\circ} \mathrm{N}$ and south of $60^{\circ} \mathrm{S}$. Water-vapor contents 


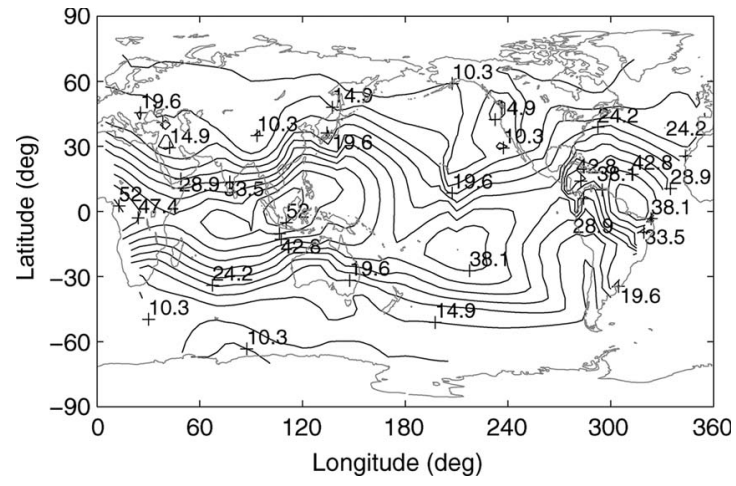

Fig. 4. Distribution of mean PWV (in millimeters) from global IGS observations for 1994-2007. The mean PWV at each site was calculated from the 2-h PWV time series for 13 years.

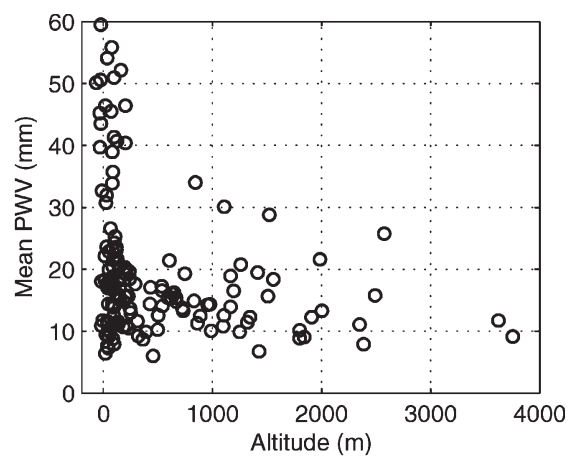

Fig. 5. Distribution of mean PWV with the elevation. The circle represents the mean PWV at each site.

over high elevations are generally lower (Fig. 5), decreasing with the increase of the elevation, which may be caused by a colder atmosphere over the high-elevation areas (Fig. 6). Fig. 7 shows a comparison of mean PWV and mean temperatures at IGS sites, reflecting that the distributions of atmospheric water vapors are mainly related to the temperature. In addition, the denser PWV distributions show a regionally distributed feature. For example, the high PWV in Southeast Asia-North Australia may reflect the influence of the Asian and west Pacific monsoons [37]. Higher PWV in southeast of the Tibet are due to water-vapor transportation from the Bay of Bengal and adjacent areas [38]. At the same latitude, the water vapor in western China is lower than in eastern China, which may be caused by a colder atmosphere over the high, snow-covered surface over the western areas, i.e., Tibet [39]. Therefore, the distribution of atmospheric water vapor in the globe is mainly dominated by the latitude, topographical features, and climatic conditions.

We analyzed the PWV time series at all IGS GPS stations with fast Fourier transform and found that the most marked periods of all GPS stations' PWV time series are about 1 year and 0.5 year in the low frequent variation, and 1 day and 0.5 day in the high frequent variation. In order to further investigate the water-vapor climatology and variability at annual and diurnal scales, the PWV time series are analyzed by a harmonic function with annual, semiannual, diurnal, and semidiurnal components as follows:

$$
P W V_{\mathrm{t}}=a+\sum_{k=1}^{4}\left[c_{k} \sin \left(2 \pi\left(t-t_{0}\right) / p_{k}+\varphi_{k}\right)\right]+\varepsilon_{\mathrm{t}}
$$

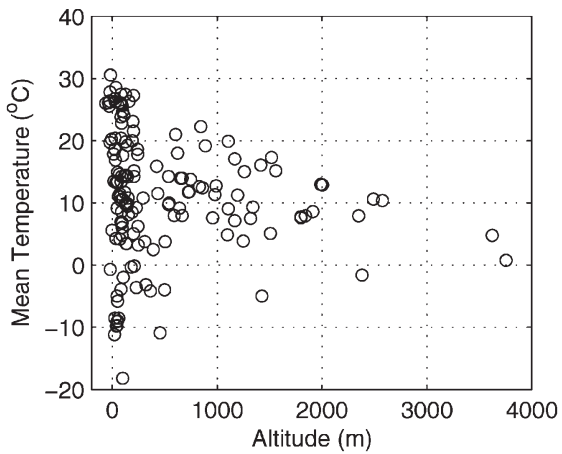

Fig. 6. Distribution of mean temperature (in degree Celsius) at each IGS site with the elevation. The circle represents the mean temperature at each site.

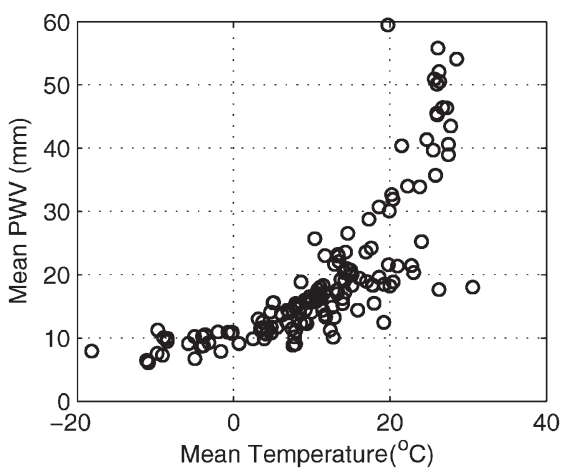

Fig. 7. Comparison of mean PWV and mean temperatures at each IGS site.

where $a$ is the constant, $c_{k}$ and $\varphi_{k}$ are the amplitude and phase at period $p_{k}$ (=1 year, 0.5 year, 1 day, and 0.5 days), respectively, and $\varepsilon$ is the residual. Through the method of least squares we can determine the unknown parameters in (5) with the original 13-year PWV time series at 2-h interval, e.g., amplitudes and phases of PWV variations at annual, semiannual, diurnal, and semidiurnal time scales as well as their uncertainties, and then we further analyze the characteristics of annual, semiannual, diurnal, and semidiurnal PWV variations. Here, the trends are not analyzed due to short observation period for 1994 to 2007, which are unlikely to be a good fit to the data given ENSO and other large natural variability.

\section{A. Seasonal Variations of Water Vapor}

The annual cycle of water vapor reflects the atmospheric process and circulation patters. Fig. 8 shows the amplitude (in units of millimeters) of annual PWV variations from global IGS observations. The higher amplitudes are found in midlatitudes with about $10-20 \pm 0.5 \mathrm{~mm}$, and the lower amplitudes with about $5 \pm 0.5 \mathrm{~mm}$ are located in high latitudes and equatorial areas (Fig. 9). The peak of maximum water-vapor concentration is in summer, i.e., July-August for the Northern Hemisphere and January-February for the Southern Hemisphere (Fig. 10). In contrast, the minimum water-vapor content is in winter. The strong seasonal cycles in summer with a maximum water vapor are due to the influence of a moist summer monsoon and minimum water vapors in winter are due to a cold temperature. The mean PWV differences between June-July-August (JJA) and December-January-February (DJF) are shown in Fig. 11 


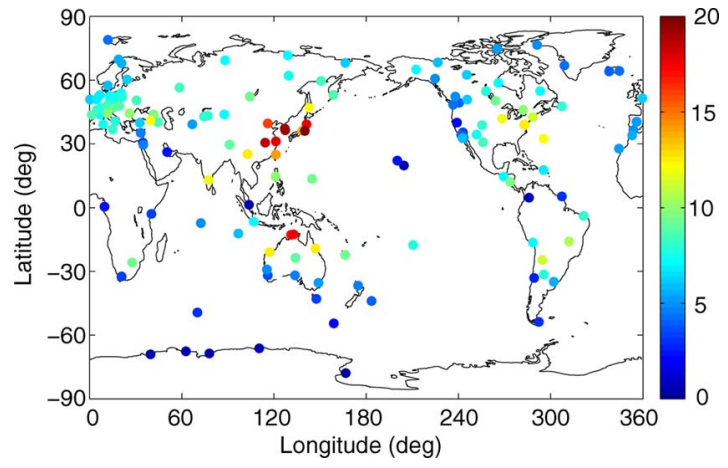

Fig. 8. Amplitude (in millimeters) of annual PWV variations from global IGS observations.

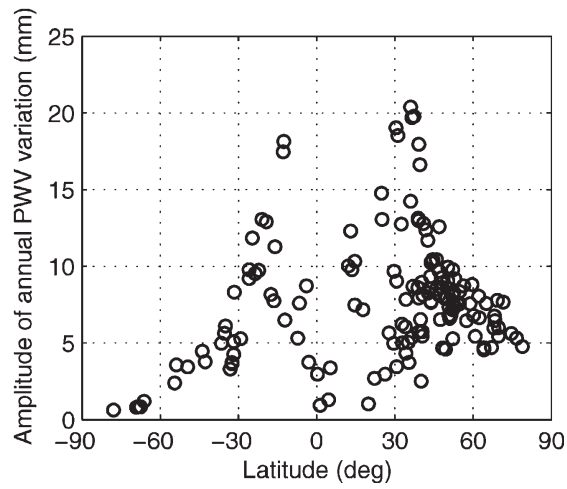

Fig. 9. Distribution of annual PWV variation amplitude with the latitude.

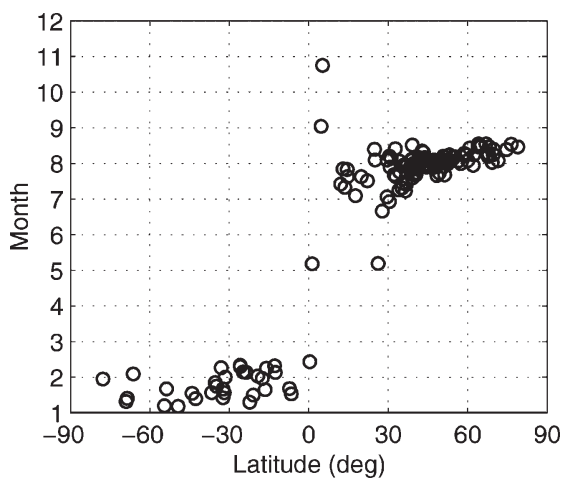

Fig. 10. Distributions of annual peak PWV phases with the latitude.

with the latitude distributions and the larger differences of PWV are located in midlatitudes, about $30^{\circ} \mathrm{S}$ and $30^{\circ} \mathrm{N}$, particularly in the Northern Hemisphere with about $10-30 \mathrm{~mm}$. For the high latitudes, in summer and winter the PWV almost has no obvious differences in the Southern Hemisphere and but has significant differences with about $10 \mathrm{~mm}$ in the Northern Hemisphere. In addition, this discrepancy is subject to unevenly distributed GPS stations in the Northern and Southern Hemispheres. It needs to be further confirmed with much denser and longer GPS observations in the future.

The semiannual variation amplitudes are weak with about $0.5 \pm 0.2 \mathrm{~mm}$. Fig. 12 shows the amplitude of semiannual PWV variations from global IGS observations. The peak time of maximum semiannual PWV variations are about in February-April and August-October.

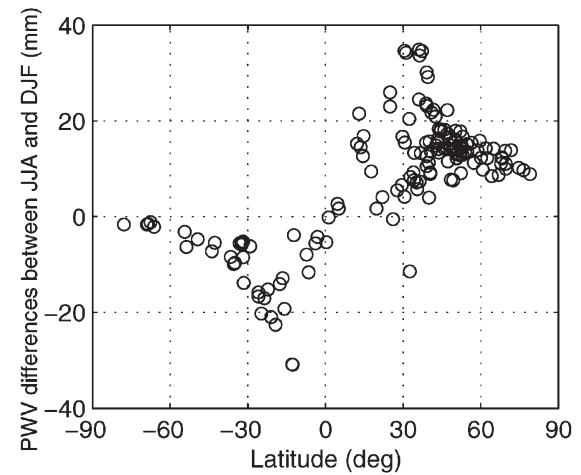

Fig. 11. Distribution of PWV differences between JJA and DJF with the latitude.

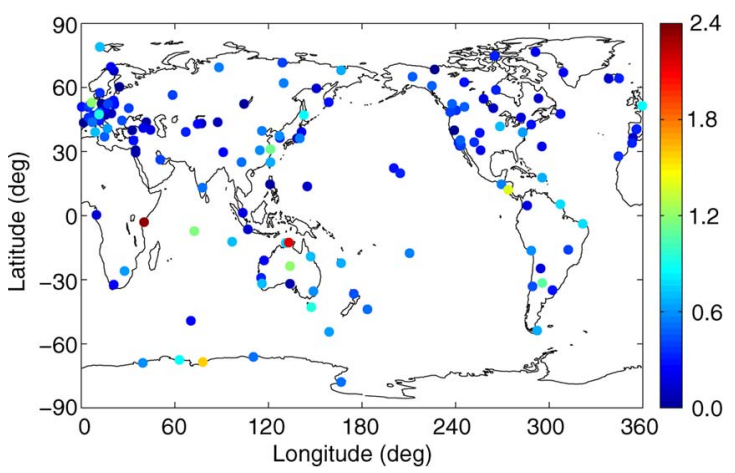

Fig. 12. Amplitude (in millimeters) of semiannual PWV variations from global IGS observations.

\section{B. Diurnal Variation of Water Vapor}

The significant diurnal variations of the water vapors are also found over all GPS stations. Fig. 13 shows amplitudes of diurnal (24 h) PWV variations $\left(S_{1}\right)$ (a) (upper panel); and phase of diurnal PWV variations (b) (bottom panel). The amplitudes of diurnal PWV variations are ranging from 0.2 to $1.2 \pm$ $0.1 \mathrm{~mm}$. The diurnal PWV cycles are stronger in summer than in winter. The diurnal PWV cycles are closely related to the temperature (Fig. 14). The peak times of diurnal PWV variations are from the noon to midnight. The semidiurnal $(12 \mathrm{~h})$ PWV variations $\left(S_{2}\right)$ are much weaker than the diurnal variations with amplitudes of less than $0.3 \mathrm{~mm}$ in difference seasons. The phase of the $S_{2}$ is noisier than that of the $S_{1}$. In general, the $\mathrm{S} 2$ peaks occur in early morning and afternoon (for the second cycle), or around midnight and noon. The diurnal PWV cycles are mainly controlled by atmospheric large-scale vertical motion, atmospheric low-level moisture convergence and precipitation, surface evapotranspiration, and other factors [23].

\section{CONCLUSION}

The 13-year PWV time series with 2-h resolution from global raw IGS observation data for 1994-2007 and global three-hourly surface weather observations and six-hourly NCEP/NCAR reanalysis products are the fist used to investigate the water-vapor climatology and variability. It has been shown that the stronger water vapors are located in low latitudes, while 
(a)

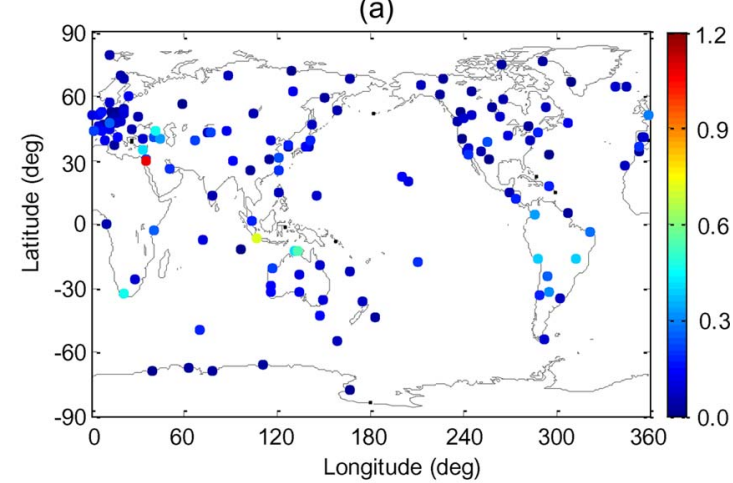

(b)

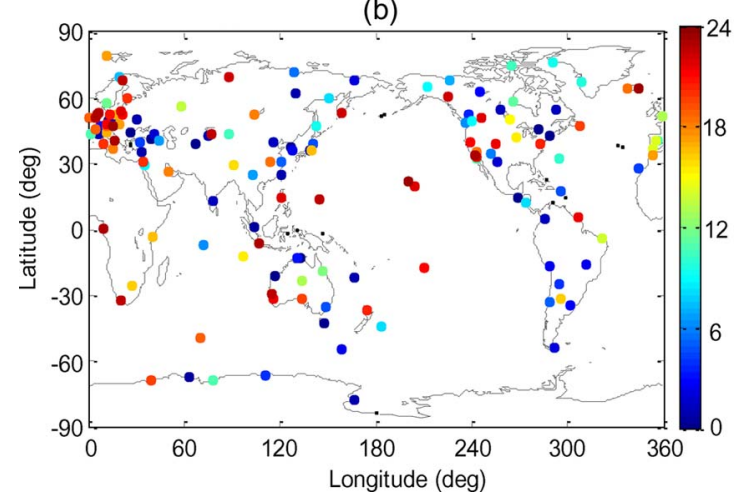

Fig. 13. Amplitude (in millimeters) of (a) diurnal PWV variations and phase (in hour) of (b) diurnal PWV variations.

high latitudes have lower water-vapor contents. The distinct season cycles are found over all IGS stations. The marked seasonal cycles are in summer with a maximum water vapor and in winter with a minimum water vapor. The higher amplitudes are located in midlatitudes with about 10-20 $\pm 0.5 \mathrm{~mm}$, and the lower amplitudes are located in high latitudes and equatorial areas with about $5 \pm 0.5 \mathrm{~mm}$. The semiannual variation amplitudes are relatively weak with about $0.5 \mathrm{~mm}$. The peak time of semiannual PWV variations are about in February-April and August-October. In addition, significant diurnal variations of PWV are found over most IGS stations. The diurnal $(24 \mathrm{~h})$ cycle has amplitude of $0.2-1.2 \pm 0.1 \mathrm{~mm}$, which is closely related to the temperature, and the peak time is about from the noon to midnight. The semidiurnal $(12 \mathrm{~h})$ cycle is weaker, with amplitude of less than $0.3 \mathrm{~mm}$.

With the development and increase of existing IGS stations and regional permanent GPS network, such as national Crustal Movement Observation Network of China with about 30 continuous GPS sites, GPS Earth Observation Network of Japan with about 1000 continuous GPS sites, and Korean GPS Network with about 80 continuous GPS sites, etc., it will provide denser GPS observations. Meanwhile, recent GPS radio occultation missions (e.g., CHAMP/GRACE, Formosat-3/ COSMIC, and TerraSAR-X) also provide high spatial global water-vapor estimations. In the next phase, we will produce denser and near-real time water-vapor data set with all available continuous GPS and radio occultation observations as well as other satellite observations, which will soon be archived in the global IGS data center (ftp://nfs.kasi.re.kr).

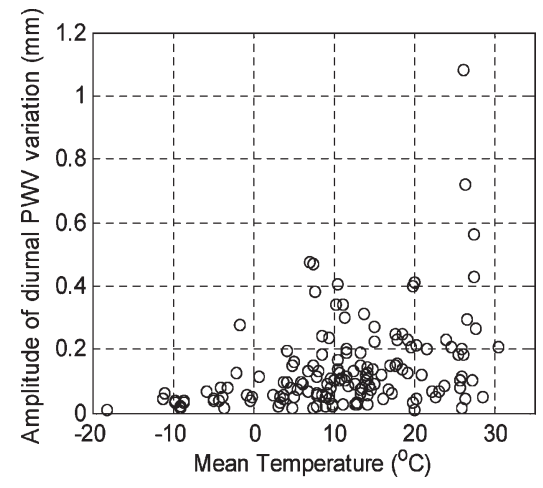

Fig. 14. Distribution of diurnal PWV variation amplitudes with the mean temperature.

\section{ACKNOWLEDGMENT}

The authors would like to thank three reviewers for constructive comments and useful suggestions to improve the manuscript as well as IGS for providing highly precise GPS observations data.

\section{REFERENCES}

[1] B. Fontaine, P. Roucou, and S. Trzaska, "Atmospheric water cycle and moisture fluxes in the West African monsoon: Mean annual cycles and relationship using NCEP/NCAR reanalysis," Geophys. Res. Lett., vol. 30 , no. 3, p. 1117, Feb. 2003. DOI: 10.1029/2002GL015834.

[2] J. K. Bannon and L. P. Steel, "Averaged water vapor contents of the air," Geophysical Memo. 102, 1960, U.K.: Meteorol. Office.

[3] V. P. Starr, J. P. Peixoto, and A. R. Crisi, "Hemispheric water balance for the IGY," Tellus, vol. 17, pp. 463-471, 1965.

[4] B.-C. Gao, P. K. Chan, and R.-R. Li, "A global water vapor data set obtained by merging the SSMI and MODIS data," Geophys. Res. Lett., vol. 31, no. 18, p. L18 103, Sep. 2004. DOI: 10.1029/2004GL020656.

[5] D. J. Gaffen, W. P. Elliott, and A. Robock, "Relationships between tropospheric water vapor and surface temperature as observed by radiosondes," Geophys. Res. Lett., vol. 19, no. 18, pp. 1839-1879, 1992.

[6] W. R. Elliott, R. J. Ross, and D. J. Gaffen, "Water vapor trends over North America," in Proc. 6th Symp. Global Change Studies, Dallas, TX, 1995, pp. 185-186. Preprints.

[7] S. A. Tjemkes, G. L. Stephens, and D. L. Jackson, "Spaceborne observation of columnar water vapor-SSMI observations and algorithm," $J$. Geophys. Res., vol. 96, no. D6, pp. 10 941-10 954, Jun. 1991.

[8] M. Bevis, S. Businger, S. Chiswell et al., "GPS meteorology: Mapping zenith wet delays onto precipitable water," J. Appl. Meteorol., vol. 33, no. 3, pp. 379-386, Mar. 1994.

[9] M. Hernandez-Pajares, J. Juan, J. Sanz et al., "A new strategy for real-time integrated water vapor determination in WADGOPS networks," Geophy. Res. Lett., vol. 28, no. 17, pp. 3267-3270, 2001.

[10] P. Basili, S. Bonafoni, V. Mattioli, P. Ciotti, and N. Pierdicca, "Mapping the atmospheric water vapor by integrating microwave radiometer and GPS measurements," IEEE Trans. Geosci. Remote Sens., vol. 42, no. 8, pp. 1657-1665, Aug. 2004.

[11] V. Mattioli, E. R. Westwater, S. Gutman, and V. Morris, "Forward model studies of water vapor using scanning microwave radiometers, Global Positioning System, and radiosondes during the cloudiness intercomparison experiment," IEEE Trans. Geosci. Remote Sens., vol. 43, no. 5, pp. 1012 1021, May 2005.

[12] T. Nilsson and L. Gradinarsky, "Water vapor tomography using GPS phase observations: Simulation results," IEEE Trans. Geosci. Remote Sens., vol. 44, no. 10, pp. 2927-2941, Oct. 2006.

[13] S. G. Jin, J. U. Park, J. H. Cho, and P. H. Park, "Seasonal variability of GPS-derived Zenith tropospheric delay (1994-2006) and climate implications," J. Geophys. Res., vol. 112, no. D9, p. D09 110, May 2007. DOI: 10.1029/2006JD007772.

[14] E. Westwater, "Ground-based microwave remote sensing of meteorological variables," in Atmospheric Remote Sensing by Microwave Radiometry, M. A. Janssen, Ed. New York: Wiley, 1993, pp. 145-213. 
[15] G. Elgered, J. Johansson, B. Rönnäng, and J. Davis, "Measuring regional atmospheric water vapor using the Swedish permanent GPS network," Geophys. Res. Lett., vol. 24, no. 21, pp. 2663-2666, Nov. 1997.

[16] C. Rocken, R. Ware, T. Van Hove, F. Solheim, C. Alber, J. Johnson, and M. Bevis, "Sensing atmospheric water vapor with the Global Positioning System," Geophys. Res. Lett., vol. 20, no. 23, pp. 2631-2634, Dec. 1993.

[17] J. Duan, M. Bevis, P. Fang et al., "GPS Meteorology: Direct estimation of the absolute value of precipitable water," J. Appl. Meteorol., vol. 35, no. 6, pp. 830-838, Jun. 1996.

[18] T. R. Emardson, G. Elgered, and J. M. Johansson, "Three months of continuous monitoring of atmospheric water vapor with a network of Global Positioning System receivers," J. Geophys. Res., vol. 103, no. D2, pp. 1807-1820, 1998.

[19] P. Tregoning, R. Boers, and D. O'Brien, "Accuracy of absolute precipitable water vapor estimates from GPS observations," J. Geophys. Res., vol. 103, no. D22, pp. 28701-28 710, Nov. 1998.

[20] A. Memmon, E. Fionda, T. Paolucci, D. Cimini, R. Ferreti, S. Bonafoni, and P. Ciotti, "Comparison of MM5 integrated water vapor with microwave radiometer, GPS, and radiosonde measurements," IEEE Trans. Geosci. Remote Sens., vol. 43, no. 5, pp. 1050-1058, May 2005.

[21] Y.-H. Kuo, Y. R. Guo, and E. R. Westwater, "Assimilation of precipitable water measurements into a mesoscale numerical model," Mon. Weather Rev., vol. 121, no. 4, pp. 1215-1238, Apr. 1993.

[22] G. Gendt, G. Dick, C. Reigber, M. Tomassini, Y. Liu, and M. Ramatschi, "Near real time GPS water vapor monitoring for numerical weather prediction in Germany," J. Meteorol. Soc. Jpn., vol. 82, no. 1B, pp. 361-370, 2004.

[23] A. Dai, J. Wang, R. H. Ware, and T. Van Hove, "Diurnal variation in water vapor over North America and its implications for sampling errors in radiosonde humidity," J. Geophys. Res., vol. 107, no. D10, p. 4090, May 2002. DOI: 10.1029/ 2001JD000642.

[24] P.-M. Wu, J.-I. Hamada, S. Mori, Y. I. Tauhid, M. D. Yamanaka, and F. Kimura, "Diurnal variation of precipitable water over a mountainous area of Sumatra Island," J. Appl. Meteorol., vol. 42, no. 8, pp. 1107-1115, Aug. 2003.

[25] T. Schueler, A. Posfay, G. W. Hein, and R. Biberger, "A global analysis of 557 the mean atmospheric temperature for GPS water vapor estimation," in Proc. 14th Int. Tech. Meeting Satell.-C5: 558 Atmospheric Effects, IONGPS, 2001, p. 559.

[26] J. Wang, L. Y. Zhang, A. Dai, T. Van Hove, and J. Van Baelen, "A near-global, 2-hourly data set of atmospheric precipitable water from ground-based GPS measurements," J. Geophys. Res., vol. 112, no. D11, p. D11 107, Jun. 2007. DOI: 10.1029/2006JD007529.

[27] G. Beutler, M. Rothacher, S. Schaer, T. A. Springer, J. Kouba, and R. E. Neilan, "The international GPS service (IGS): An interdisciplinary service in support of earth sciences," Adv. Space Res., vol. 23, no. 4, pp. 631-653, 1999.

[28] T. Humphreys, M. Kelley, and P. Kintner, "GPS-based measurements of atmospheric tides," in Proc. ION GNSS Conf., Inst. Navig., Long Beach, CA, Sep. 21-24, 2004, pp. 864-880.

[29] R. W. King and Y. Bock, Documentation for the GAMIT GPS analysis software. Cambridge, MA: Massachussets Inst. Technol., 2005.

[30] S. Byun, Y. Bar-Sever, and G. Gendt, "The new tropospheric product of the International GNSS service," in Proc. ION GNSS Conf., Inst. Navig., Long Beach, CA, 2005.

[31] S. G. Jin, O. F. Luo, and S. Gleason, "Characterization of diurnal cycles in ZTD from a decade of global GPS observations," J. Geod., vol. 83, Jun. 2009. DOI: 10.1007/s00190-008-0264-3.
[32] J. Davis, T. A. Herring, I. Shapiro, A. Rogers, and G. Elgered, "Geodesy by radio interferometry: Effects of atmospheric modeling errors on estimates of baseline length," Radio Sci., vol. 20, no. 6, pp. 1593-1607, Nov./Dec. 1985.

[33] A. Dai and J. Wang, "Diurnal and semidiurnal tides in global surface pressure fields," J. Atmos. Sci., vol. 56, no. 22, pp. 3874-3891, Nov. 1999.

[34] D. Behrend, L. Cucurull, J. Vila, and R. Haas, "An inter-comparison study to estimate zenith wet delays using VLBI, GPS, and NWP models," Earth Planets Space, vol. 52, no. 10, pp. 691-694, 2000.

[35] K. Snajdrova, J. Boehm, P. Willis, R. Haas, and H. Schuh, "Multitechnique comparison of tropospheric zenith delays derived during the CONT02 campaign," J. Geod., vol. 79, no. 10/11, pp. 613-623, Feb. 2005.

[36] A. Niell, A. J. Coster, F. S. Solheim, V. B. Mendes, P. C. Toor, R. B. Langley, and C. A. Upham, "Comparison of measurements of atmospheric wet delay by radiosonde, water vapor radiometer, GPS, and VLBI," J. Atmos. Ocean. Technol., vol. 18, no. 6, pp. 830-850, Jun. 2001.

[37] C. P. Chang, East Asian Monsoon. Singapore: World Scientific, 2004.

[38] J. S. Zou, J. Jiang, and M. H. Huang, Upper-Air Climatology. Meteorological Press, Beijing, 1999.

[39] S. G. Jin, Z. Li, and J. Cho, "Integrated water vapor field and multiscale variations over China from GPS measurements," J. Appl. Meteorol. Climatol., vol. 47, no. 11, pp. 3008-3015, Nov. 2008.

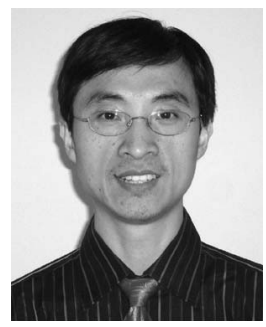

Shuanggen Jin (M'05) was born in Anhui, China, on September 3, 1974. He received the B.Sc. degree in geodesy/surveying from Wuhan University, Wuhan, China, in 1999 and the Ph.D. degree in GPS/geophysics from the Chinese Academy of Sciences, Shanghai, China, in 2003.

Since 2004, he has been with the University of New South Wales, Sydney, Australia; Korea Astronomy and Space Science Institute (KASI), Daejeon, Korea; Korea University of Science and Technology (UST), Daejeon; Royal Observatory of Belgium, Brussels, Belgium; Taiwan National Central University, Taoyuan, Taiwan; and Center for Space Research (CSR), The University of Texas at Austin, Austin. He is currently a Research Scientist with CSR, Senior Scientist with KASI, and Professor with UST. He has published over 70 peer-reviewed journal papers as the lead author in J. Geophys. Res., Earth Planet. Sci. Lett., Geophys. J. Int., IEEE Trans. Geosci. Remote Sens., J. Geodyn., J. Geod., etc., as well as over 80 conference proceedings papers. His research interests include Global Navigation Satellite Systems (GNSS)/InSAR/Gravity Geodesy and Remote Sensing, Satellite Navigation and Positioning, GNSS Meteorology and Atmospheric/Ionospheric Sounding, Satellite Oceanography, Solid-Earth Geophysics, and Space/Planetary Sciences, etc.

Dr. Jin has been Chairman of the International Association of Geodesy Study Group 4.1 (2007-2011) and Convener/Chair of many sessions at international conferences (AGU, EGU, IAG, AOGS, IEEE...) as well as Reviewer for various international journals, proceedings and proposals. He has received several awards including Special Prize, KASI in 2006.

O. F. Luo was born in Hangzhou, China, on April 2, 1978. She is currently working toward the M.S. degree in Chungnam National University, Daejeon, Korea. 